\title{
Photochemically-enhanced Selective Adsorption of Gold Ions on Tannin-coated Porous Polymer Microspheres
}

Jeonga Kim¹, Kyeong Rak Kim¹, Yeongran Hong' ${ }^{2}$, Sunyoung Choi ${ }^{3}$, Cafer T. Yavuz ${ }^{2,4,5}$, Jin Woong Kim ${ }^{6,7, *}$ and Yoon Sung Nam ${ }^{1,8, *}$

${ }^{1}$ Department of Materials Science and Engineering, Korea Advanced Institute of Science and Technology, 291 Daehak-ro, Yuseong-gu, Daejeon, 34141, Republic of Korea

${ }^{2}$ Graduate School of Energy, Environment, Water and Sustainability (EEWS), Korea Advanced Institute of Science and Technology, 291 Daehak-ro, Yuseong-gu, Daejeon, 34141, Republic of Korea

${ }^{3}$ CTK Cosmetics, 255 Pangyo-ro, Seongnam-si, Gyeonggi-do, 13486, Republic of Korea

${ }^{4}$ Department of Chemical and Biomolecular Engineering, and ${ }^{5}$ Department of Chemistry, Korea Advanced Institute of Science and Technology, 291 Daehak-ro, Yuseong-gu, Daejeon, 34141, Republic of Korea

${ }^{6}$ Department of Bionano Technology and ${ }^{7}$ Department of Chemical and Molecular Engineering, Hanyang University, Ansan 15588, Republic of Korea

${ }^{8}$ KAIST Institute for NanoCentury, Korea Advanced Institute of Science and Technology, 291 Daehak-ro, Yuseong-gu, Daejeon, 34141, Republic of Korea

*Address correspondence to yoonsung@kaist.ac.kr (Y.S.N.) and kjwoong@ hanyang.ac.kr (J.W.K.) 


\section{Adsorption kinetics}

The number of gold ions adsorbed on the untreated $p \mathrm{MS}$ and TA- $p \mathrm{MS}$ at time $t\left(q_{t}, \mathrm{mmol} \mathrm{g}^{-1}\right)$ was calculated by using the equation $\mathrm{S} 1$,

$$
q_{t}=\frac{C_{i}-C_{t}}{W} \times V
$$

where $C_{i}(\mathrm{mM})$ and $C_{t}(\mathrm{mM})$ are the concentrations of gold ions before and after the adsorption at time $t$, respectively, and $W(\mathrm{~g})$ and $V(\mathrm{~L})$ are the weight of the adsorbent and volume of the adsorption solution, respectively. ${ }^{1}$

The pseudo-first-order adsorption kinetics model is expressed as follows,

$$
\frac{d q_{t}}{d t}=k_{1}\left(q_{e}-q_{t}\right)
$$

where $q_{e}\left(\mathrm{mmol} \mathrm{g}^{-1}\right)$ and $q_{t}\left(\mathrm{mmol} \mathrm{g}^{-1}\right)$ are the number of gold ions adsorbed on the adsorbent at equilibrium and at adsorption time, $t(\mathrm{~min})$, respectively, and $k_{1}\left(\mathrm{~min}^{-1}\right)$ is the pseudo-first-order rate constant ${ }^{1}$. Integration of the equation $\mathrm{S} 2$ with the initial condition $(q=0$ at $t=0)$ is given as

$$
\log \left(q_{e}-q_{t}\right)=\log q_{e}-\frac{k_{1}}{2.303} t
$$

which is used to calculate $q_{e}$ and $k_{l}$ by plotting the relationship between $\log \left(q_{e^{-}} q_{t}\right)$ and $t$, as shown in Figure S1A.

On the other hand, the pseudo-second-order kinetics model is expressed as follows,

$$
\frac{d q_{t}}{d t}=k_{2}\left(q_{e}-q_{t}\right)^{2}
$$


where $q_{e}\left(\mathrm{mmol} \mathrm{g}^{-1}\right)$ and $q_{t}\left(\mathrm{mmol} \mathrm{g}^{-1}\right)$ are the number of metal ions adsorbed on the adsorbent at equilibrium and at adsorption time, $t(\mathrm{~min})$, respectively, and $k_{2}\left(\mathrm{~g} \mathrm{mmol}^{-1} \mathrm{~min}^{-1}\right)$ is the rate constant of pseudo-second-order model. ${ }^{2}$ Integration of the equation S4 with the initial condition $(q=0$ at $t=0)$ is given as

$$
\frac{t}{q_{t}}=\frac{1}{k_{2} q_{e}^{2}}+\frac{1}{q_{e}} t
$$

which is used to calculate $q_{e}$ and $k_{2}$ by plotting the relationship between of $t / q_{t}$ and $t$, as shown in Figure S1B. In addition, the initial adsorption rate $\left(h, \mathrm{mmol} \mathrm{g}^{-1} \mathrm{~min}^{-1}\right)$ is obtained by $h=k_{2} q_{e}^{2}$ to evaluate the initial adsorption kinetics. Correlation coefficients $\left(R^{2}\right)$ and kinetic parameters are summarized in Table S1. 

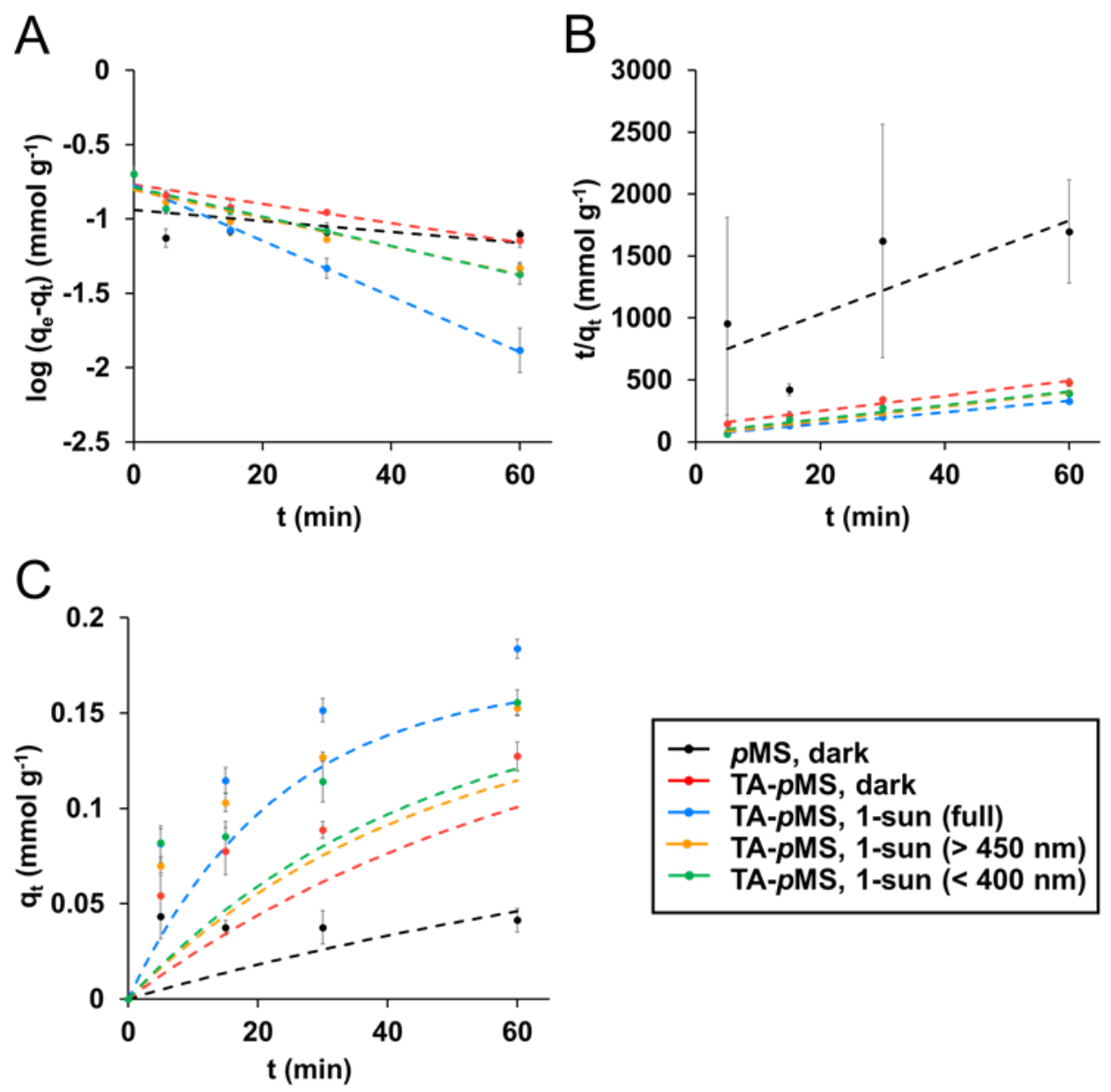

Figure S1. (A) Plot of $\log \left(q_{e^{-}} q_{t}\right)$ vs. $t$ from the pseudo-first-order model for $p \mathrm{MS}$ and TA- $p \mathrm{MS}$ (points: experimental data, dashed lines: results of the integral equation fitting of the pseudo-firstorder model) (B) Plot of $t / q_{t}$ vs. $t$ from the pseudo-second-order model for $p \mathrm{MS}$ and TA- $p \mathrm{MS}$ (points: experimental data, dashed lines: results of the integral equation fitting of the pseudo-firstorder model) (C) Adsorption kinetics of gold ions on $p \mathrm{MS}$ and TA- $p \mathrm{MS}$ (points: experimental data, dashed lines: results of the pseudo-second-order model fitting) Box: legends for (A-C). 
Table S1. Correlation coefficients and kinetic parameters obtained from the adsorption kinetics model equations.

\begin{tabular}{|c|c|c|c|c|c|c|c|}
\hline \multirow{2}{*}{ Samples } & \multicolumn{2}{|c|}{ Pseudo-first-order model } & \multicolumn{4}{|c|}{ Pseudo-second-order model } \\
\cline { 2 - 8 } & $\begin{array}{c}k_{1} \\
\left(\mathrm{~min}^{-1}\right)\end{array}$ & $\begin{array}{c}q_{e} \\
\left(\mathrm{mmol} \mathrm{g}^{-1}\right)\end{array}$ & $R^{2}$ & $\begin{array}{c}k_{2} \\
\left(\mathrm{~g} \mathrm{mmol}^{-1}\right. \\
\left.\mathrm{min}^{-1}\right)\end{array}$ & $\begin{array}{c}q_{e} \\
\left(\mathrm{mmol} \mathrm{g}^{-1}\right)\end{array}$ & $\begin{array}{c}h(\mathrm{mmol} \\
\left.\mathrm{g}^{-1} \mathrm{~min}^{-1}\right)\end{array}$ & $R^{2}$ \\
\hline$p \mathrm{MS}$, dark & 0.009 & 0.115 & 0.241 & 0.541 & 0.053 & 0.002 & 0.561 \\
\hline $\begin{array}{c}\text { TA- } p \mathrm{MS}, \\
\text { dark }\end{array}$ & 0.015 & 0.170 & 0.909 & 0.287 & 0.165 & 0.008 & 0.979 \\
\hline $\begin{array}{c}\text { TA- } p \mathrm{MS}, \\
1-\mathrm{sun} \\
(>450 \mathrm{~nm})\end{array}$ & 0.022 & 0.157 & 0.908 & 0.615 & 0.173 & 0.018 & 0.995 \\
\hline $\begin{array}{c}\text { TA- } p \mathrm{MS}, \\
1-\mathrm{sun} \\
(<400 \mathrm{~nm})\end{array}$ & 0.023 & 0.163 & 0.930 & 0.423 & 0.179 & 0.014 & 0.938 \\
\hline $\begin{array}{c}\text { TA- } p \mathrm{MS}, \\
1-\mathrm{sun}(\mathrm{full})\end{array}$ & 0.043 & 0.168 & 0.987 & 0.411 & 0.215 & 0.019 & 0.992 \\
\hline
\end{tabular}




\section{Adsorption isotherm}

The number of gold ions adsorbed on the untreated $p \mathrm{MS}$ and TA- $p \mathrm{MS}(q, \mathrm{mmol} \mathrm{g}-1)$ were calculated by using the equation S6,

$$
\mathrm{q}=\frac{C_{i}-C_{e}}{W} \times V
$$

where $C_{i}(\mathrm{mM})$ and $C_{e}(\mathrm{mM})$ are the concentrations of gold ions before and after the adsorption, respectively, and $W(\mathrm{~g})$ and $V(\mathrm{~L})$ are the weight of the adsorbents and volume of the adsorption solution, respectively.

The Langmuir isotherm model describes the adsorption on homogeneous surfaces to form a monolayer of the adsorbed species, expressed as follows,

$$
q_{e}=\frac{q_{\max } K C_{e}}{1+K C_{e}}
$$

where $C_{e}(\mathrm{mM})$ is the equilibrium concentration of the remaining gold ions after adsorption, $q_{e}$ $\left(\mathrm{mmol} \mathrm{g}^{-1}\right)$ is the number of gold ions adsorbed on the adsorbent, $q_{\max }\left(\mathrm{mmol} \mathrm{g}^{-1}\right)$ is the maximum number of gold ions adsorbed on the adsorbent, and $K\left(\mathrm{~L} \mathrm{mmol}^{-1}\right)$ is the Langmuir constant ${ }^{1}$. The Langmuir isotherm equation can be transformed to five linearized equations, which are used to determine adsorption parameters and correlation coefficients $\left(R^{2}\right)$ by applying the experimental data to each of the linearized equations (Table S2). ${ }^{3}$ The Langmuir-1 equation showed the higher values of $R^{2}$, so it was used to determine $q_{\max }$ and $K$, as shown in Table S3.

On the other hand, the Freundlich isotherm model is an empirical model describing the adsorption on heterogeneous surfaces, which results in a multilayer adsorption. This model is expressed as S8,

$$
q_{e}=K_{F} C_{e}^{1 / n}
$$


where is $K_{F}\left(\mathrm{mmol} \mathrm{g}^{-1}\right)$ is the Freundlich isotherm constant, and $n$ is a constant. The Freundlich isotherm equation can also be transformed to a linearized equation as $\mathrm{S} 9^{1}$,

$$
\log q_{e}=\log K_{F}+\frac{1}{n} \log C_{e}
$$

Correlation coefficients $\left(R^{2}\right)$ and the isotherm parameters were calculated by applying the experimental data to $\mathrm{S} 9$, as shown in Table $\mathbf{S 3}$. 
Table S2. Isotherm models and their linearized equations with the correlation coefficients.

\begin{tabular}{|c|c|c|c|}
\hline $\begin{array}{l}\text { Langmuir } \\
\text { isotherm }\end{array}$ & Linearized equation & Samples & $R^{2}$ \\
\hline \multirow[t]{5}{*}{ Langmuir-1 } & $\begin{array}{llll}1 & 1 & 1 & 1\end{array}$ & $p \mathrm{MS}$, dark & 0.9994 \\
\hline & $\overline{q_{e}}-\overline{K q_{m}} \overline{C_{e}} \quad \overline{q_{\max }}$ & TA- $p$ MS, dark & 0.9969 \\
\hline & & TA- $p$ MS, 1 -sun $(>450 \mathrm{~nm})$ & 0.9994 \\
\hline & & TA- $p$ MS, $1-\operatorname{sun}(<400 \mathrm{~nm})$ & 0.9960 \\
\hline & & TA-pMS, 1-sun (full) & 0.9982 \\
\hline \multirow[t]{5}{*}{ Langmuir-2 } & $\underline{C_{e}}=\frac{1}{C}$ & $p \mathrm{MS}$, dark & 0.8304 \\
\hline & $\overline{q_{e}}-\overline{q_{\max }} \mathrm{c}_{e}+\overline{q_{\max } K}$ & TA- $p \mathrm{MS}$, dark & 0.9946 \\
\hline & & TA- $p$ MS, 1 -sun (> $450 \mathrm{~nm})$ & 0.9899 \\
\hline & & TA- $p$ MS, 1-sun $(<400 \mathrm{~nm})$ & 0.9353 \\
\hline & & TA- $p \mathrm{MS}, 1$-sun (full) & 0.8739 \\
\hline \multirow[t]{5}{*}{ Langmuir-3 } & \multirow{5}{*}{$q_{e}=-\frac{1}{K} \frac{q_{e}}{C_{e}}+q_{\max }$} & $p \mathrm{MS}$, dark & 0.7907 \\
\hline & & TA- $p$ MS, dark & 0.9779 \\
\hline & & TA- $p$ MS, 1-sun $(>450 \mathrm{~nm})$ & 0.9507 \\
\hline & & TA- $p$ MS, 1-sun $(<400 \mathrm{~nm})$ & 0.8668 \\
\hline & & TA- $p \mathrm{MS}, 1$-sun (full) & 0.7840 \\
\hline \multirow[t]{5}{*}{ Langmuir-4 } & \multirow{5}{*}{$\frac{q_{e}}{C_{e}}=-K q_{e}+b q_{\max }$} & $p \mathrm{MS}$, dark & 0.7907 \\
\hline & & TA- $p$ MS, dark & 0.9779 \\
\hline & & TA- $p$ MS, 1-sun $(>450 \mathrm{~nm})$ & 0.9507 \\
\hline & & TA- $p$ MS, 1 -sun $(<400 \mathrm{~nm})$ & 0.8668 \\
\hline & & TA- $p \mathrm{MS}, 1$-sun (full) & 0.7972 \\
\hline \multirow[t]{5}{*}{ Langmuir-5 } & \multirow{5}{*}{$\frac{1}{C_{e}}=K q_{\max } \frac{1}{q_{e}}-K$} & $p \mathrm{MS}$, dark & 0.9994 \\
\hline & & TA- $p \mathrm{MS}$, dark & 0.9969 \\
\hline & & TA- $p$ MS, 1-sun (> $450 \mathrm{~nm})$ & 0.9937 \\
\hline & & TA- $p$ MS, 1 -sun $(<400 \mathrm{~nm})$ & 0.9960 \\
\hline & & TA- $p$ MS, 1-sun (full) & 0.9982 \\
\hline
\end{tabular}


Table S3. Correlation coefficients and isotherm parameters obtained from each of the linearized equations.

\begin{tabular}{|c|c|c|c|c|c|c|}
\hline \multirow{2}{*}{ Samples } & \multicolumn{3}{|c|}{ Langmuir isotherm } & \multicolumn{3}{c|}{ Freundlich isotherm } \\
\cline { 2 - 7 } & $\begin{array}{c}K \\
\left(\mathrm{~L} \mathrm{mmol}^{-1}\right)\end{array}$ & $\begin{array}{c}q_{\text {max }} \\
\left(\mathrm{mmol} \mathrm{g}^{-1}\right)\end{array}$ & $R^{2}$ & $\begin{array}{c}K_{F} \\
\left(\mathrm{mmol} \mathrm{g}^{-1}\right)\end{array}$ & $n$ & $R^{2}$ \\
\hline$p$ MS, dark & 0.286 & 0.204 & 0.999 & 0.052 & 1.194 & 0.995 \\
\hline TA-pMS, dark & 0.900 & 0.266 & 0.997 & 0.119 & 1.686 & 0.982 \\
\hline $\begin{array}{c}\text { TA- } p \text { MS, } \\
1 \text {-sun }>450 \text { nm })\end{array}$ & 0.601 & 0.389 & 0.998 & 0.176 & 1.141 & 0.991 \\
\hline $\begin{array}{c}\text { TA- } p \text { MS, } \\
\text { 1-sun (<400 nm })\end{array}$ & 0.256 & 0.883 & 0.999 & 0.137 & 1.506 & 0.980 \\
\hline $\begin{array}{c}\text { TA- } p \text { MS, } \\
1-\text { sun (full })\end{array}$ & 0.133 & 1.635 & 0.996 & 0.163 & 1.232 & 0.987 \\
\hline
\end{tabular}




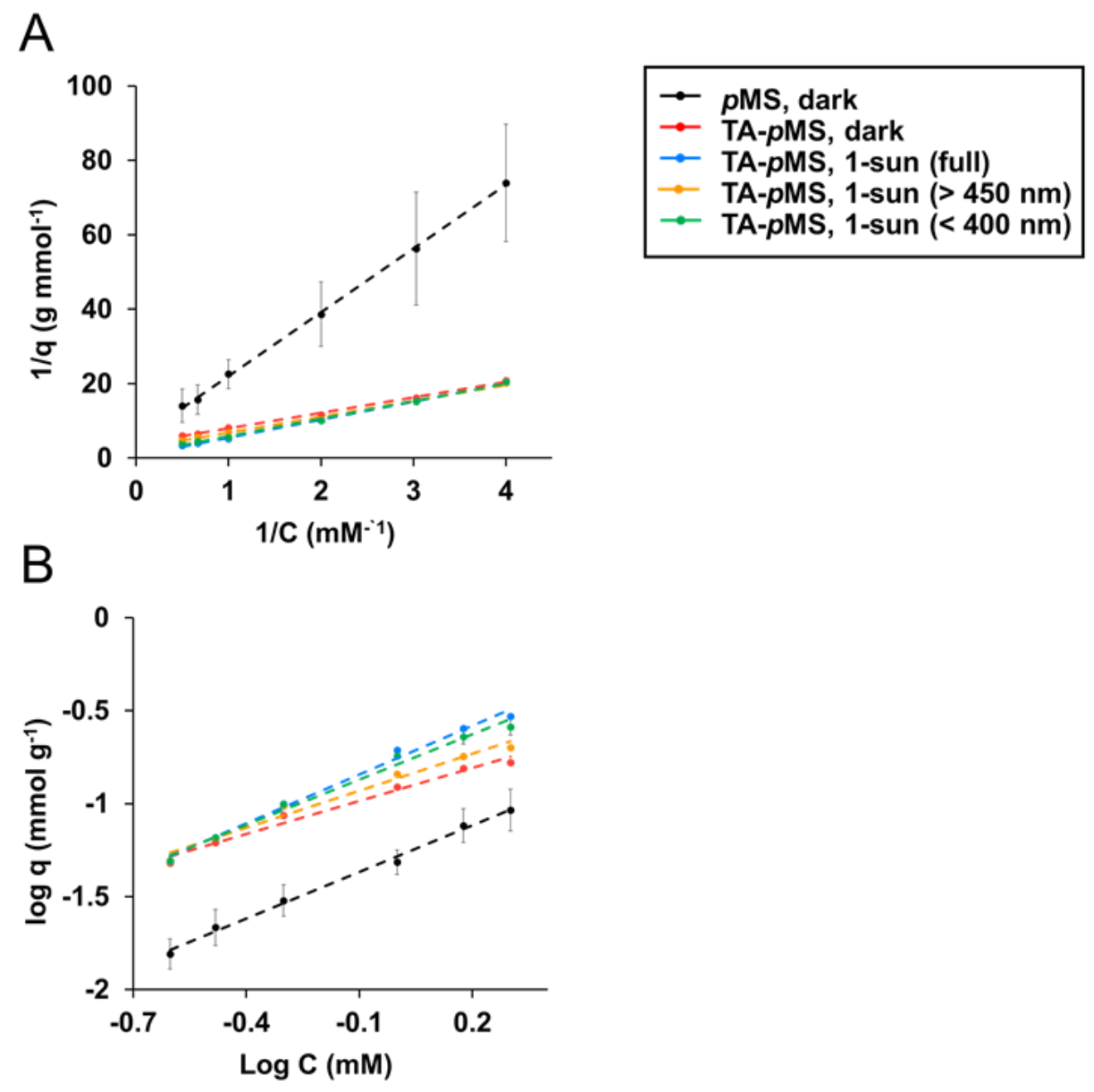

Figure S2. (A) Linearized Langmuir isotherm plots of $p \mathrm{MS}$ and TA-pMS (points: experimental data, dashed lines: results of linearized equation fitting) (B) Linearized Freundlich isotherm plots of $p \mathrm{MS}$ and TA- $p \mathrm{MS}$ (points: experimental data, dashed lines: results of linearized equation fitting) Box: legends for (A and B). 


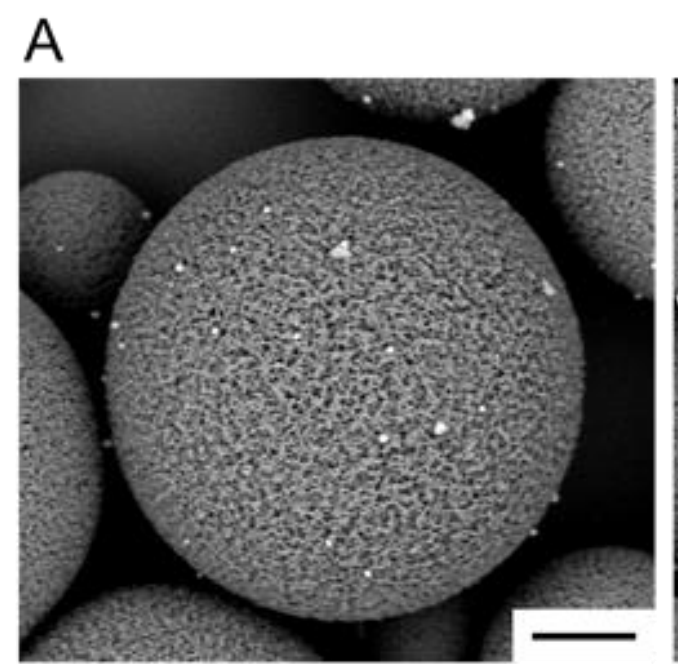

\section{B}
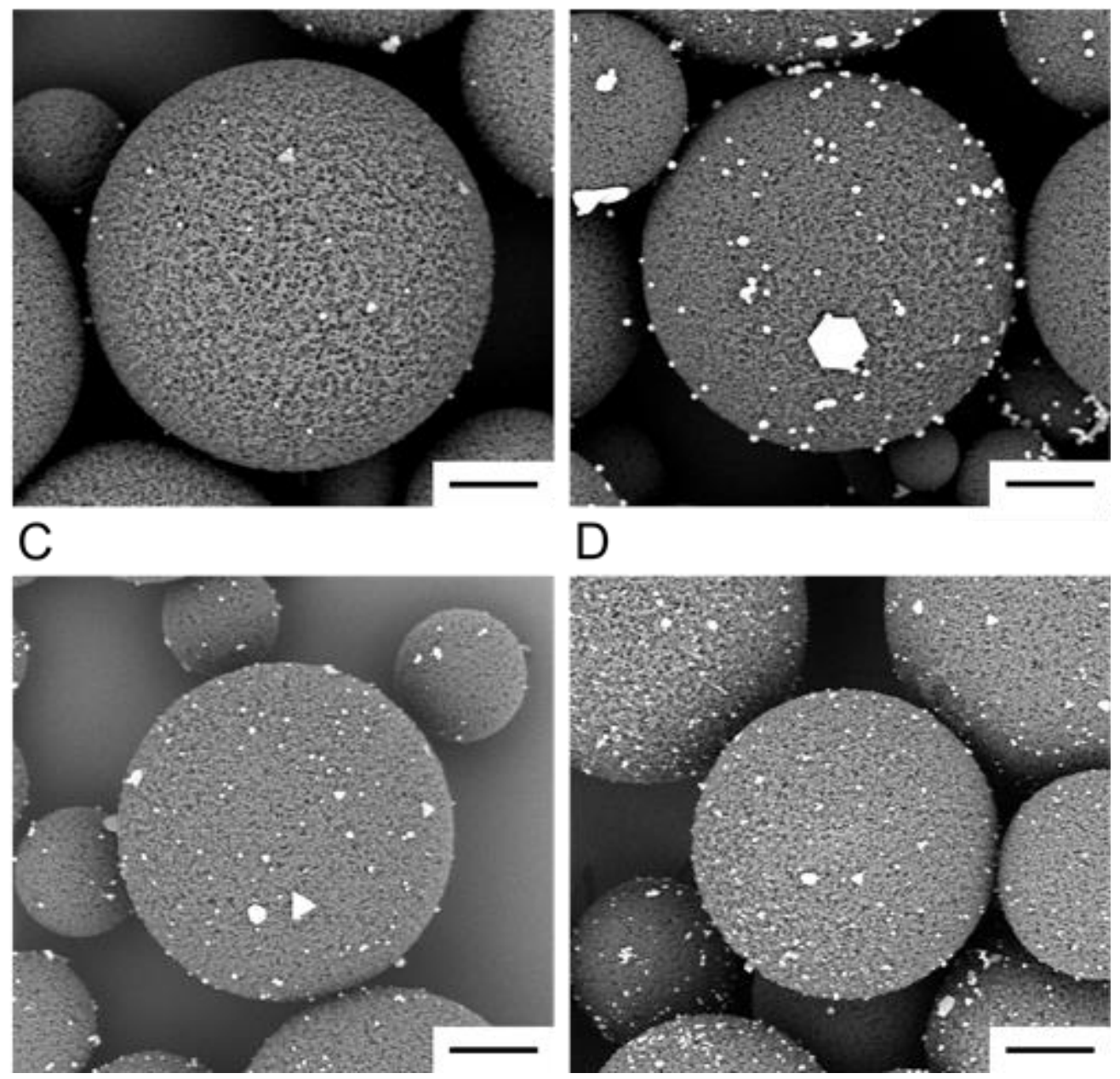

Figure S3. SEM images of Au-TA-pMS obtained from gold adsorption experiments using $1 \mathrm{mM}$ $\mathrm{HAuCl}_{4}$ for $3 \mathrm{~h}$ in the dark (A), and under 1-sun (full) (B), 1-sun (> $\left.450 \mathrm{~nm}\right)(\mathrm{C})$, and 1-sun $(<400$ $\mathrm{nm}$ ) illuminations (D). Scale bars: $3 \mu \mathrm{m}$ 


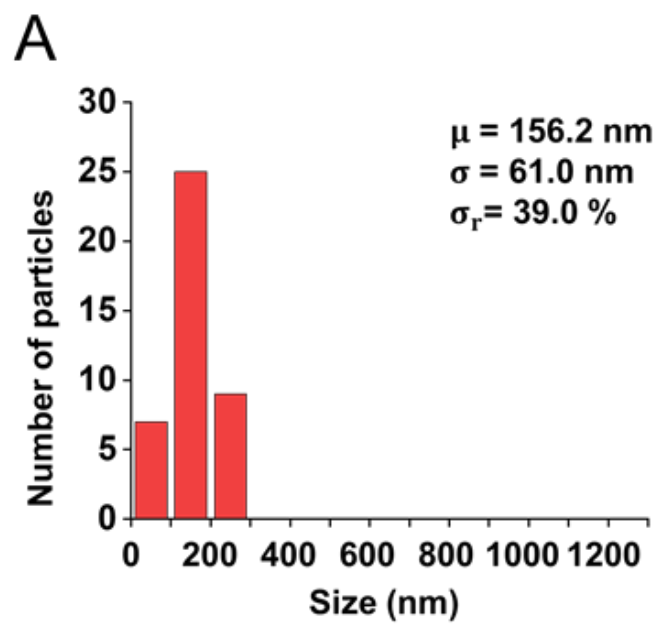

B
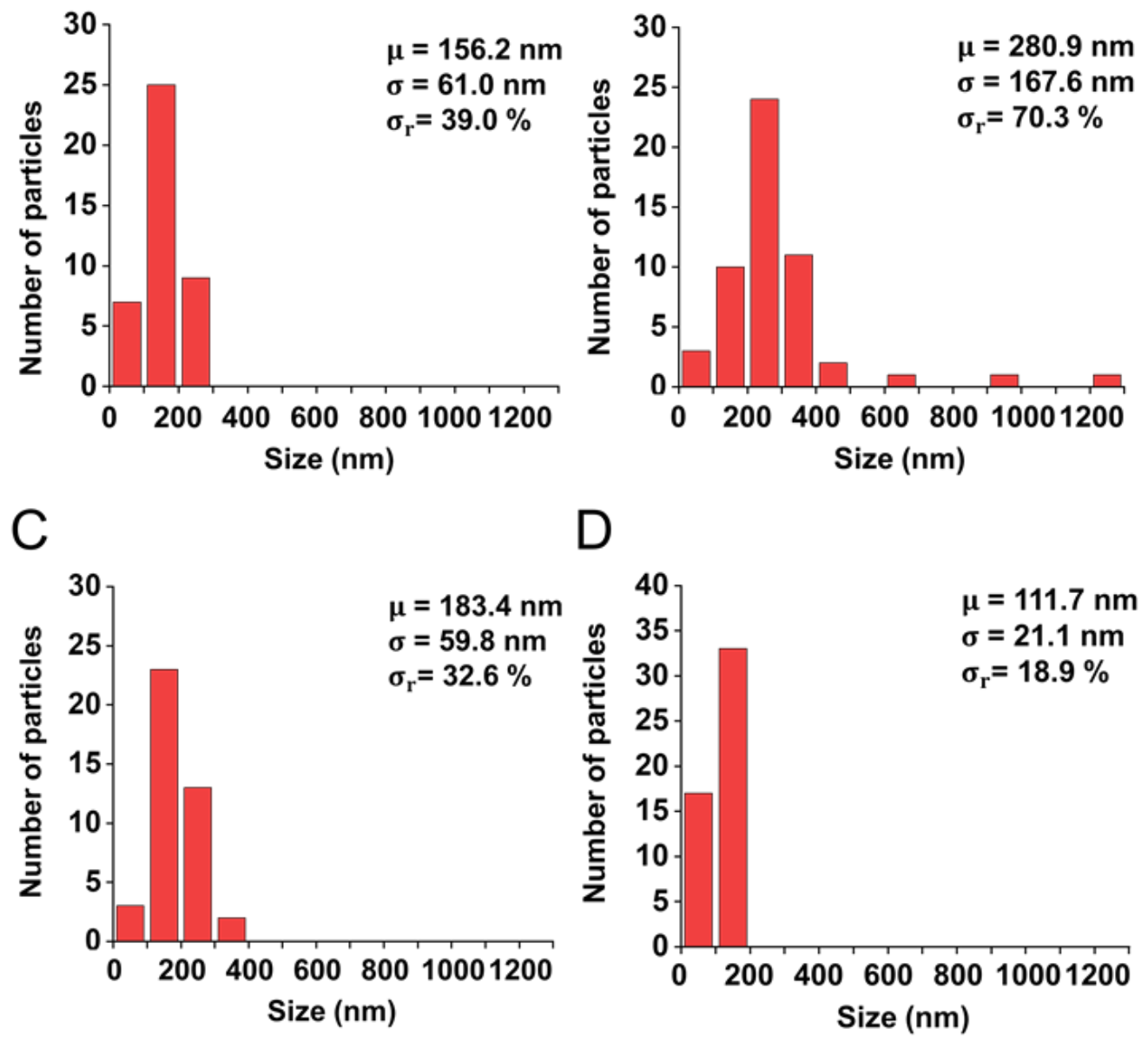

Figure S4. Size distribution histograms of gold particles measured from TEM images of Au-TA$p \mathrm{MS}$ obtained from gold adsorption experiments using $1 \mathrm{mM} \mathrm{HAuCl}_{4}$ for $3 \mathrm{~h}$ in the dark (A) and under 1 sun (B), 1 sun without UV (C), and UV (D) ( $\mu$ : average size, $\sigma$ : standard deviation, and $\sigma_{\mathrm{r}}$ : relative standard deviation). 


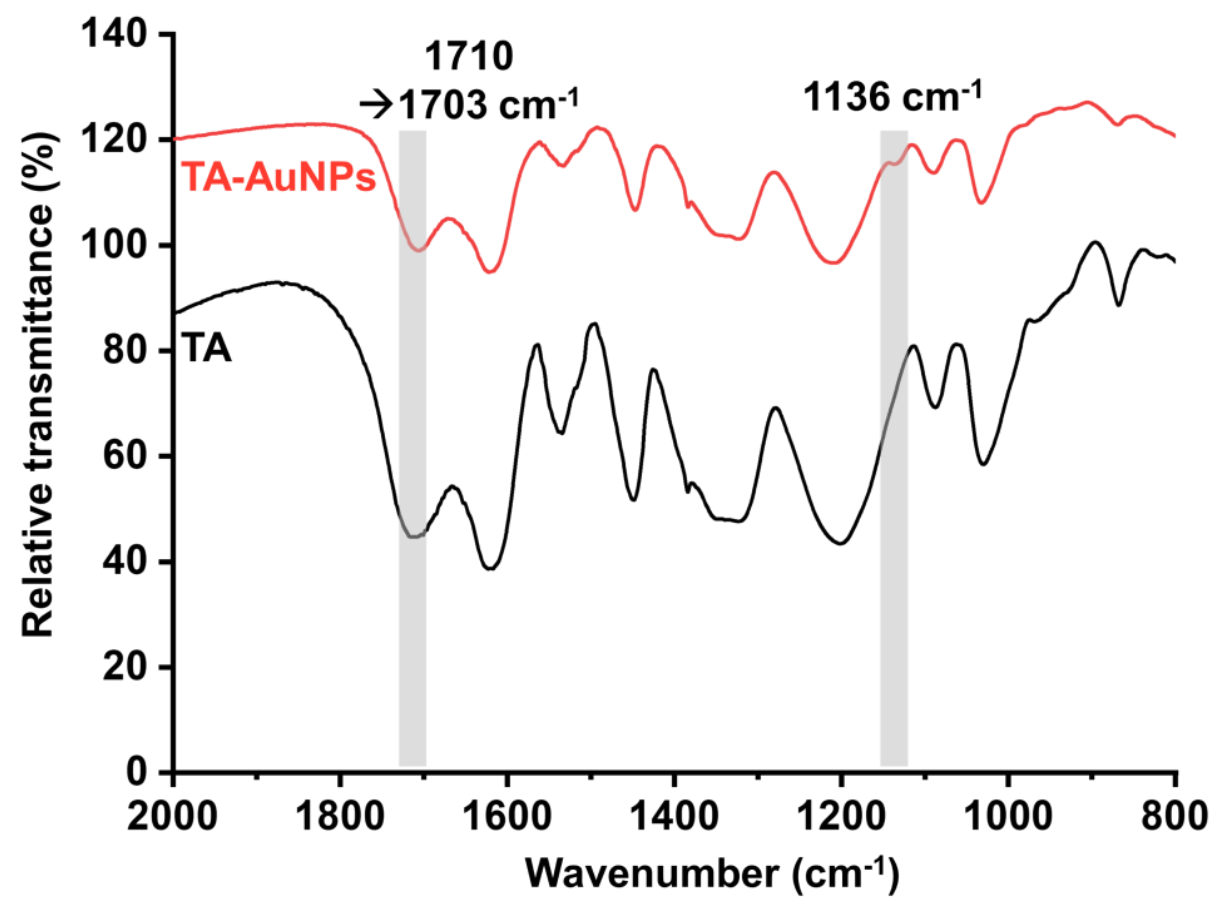

Figure S5. FT-IR spectra for TA and TA-AuNPs in the dark. 

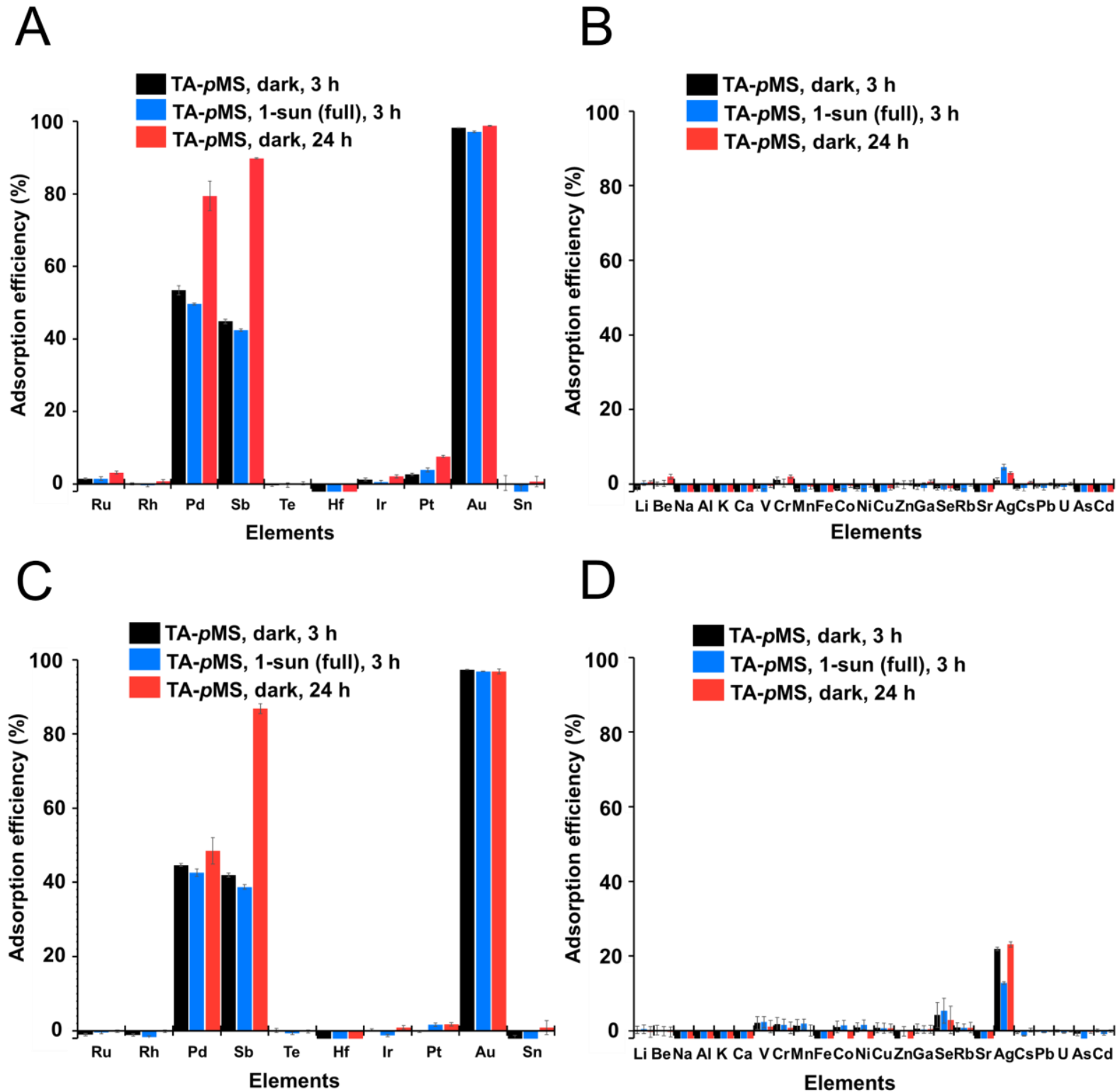

Figure S6. Adsorption percentages of various metals from the standard solution 1 (Sb, Au, Hf, Ir, $\mathrm{Pd}, \mathrm{Pt}, \mathrm{Rh}, \mathrm{Ru}, \mathrm{Te}$, and $\mathrm{Sn}$ in $10 \% \mathrm{HCl}$ and $\left.1 \% \mathrm{HNO}_{3}\right)(\mathrm{A})$, the standard solution 2 ( $\mathrm{Li}, \mathrm{Be}, \mathrm{Na}$, $\mathrm{Mg}, \mathrm{Al}, \mathrm{K}, \mathrm{Ca}, \mathrm{V}, \mathrm{Cr}, \mathrm{Mn}, \mathrm{Fe}, \mathrm{Co}, \mathrm{Ni}, \mathrm{Cu}, \mathrm{Zn}, \mathrm{Ga}, \mathrm{As}, \mathrm{Se}, \mathrm{Rb}, \mathrm{Sr}, \mathrm{Ag}, \mathrm{Cd}, \mathrm{Cs}, \mathrm{Ba}, \mathrm{Tl}, \mathrm{Pb}$, and U in $\left.5 \% \mathrm{HNO}_{3}\right)(\mathrm{B})$, and the mixture of standard solution 1 and $2(\mathrm{C}$ and $\mathrm{D})$ on TA-pMS using different adsorption times and irradiation conditions. 


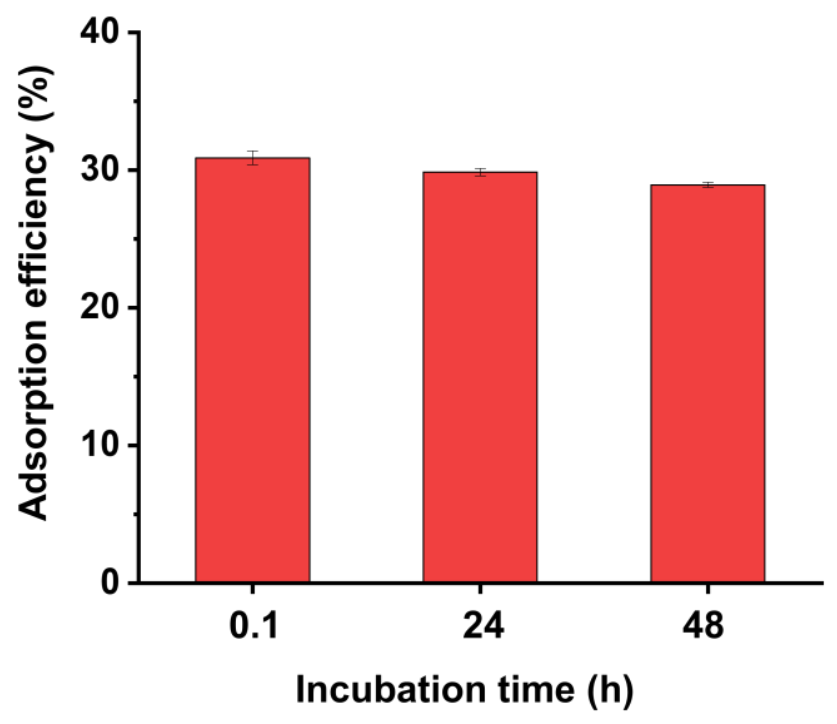

Figure S7. Adsorption efficiency of gold ions on TA- $p \mathrm{MS}$ in deionized water in the dark. 

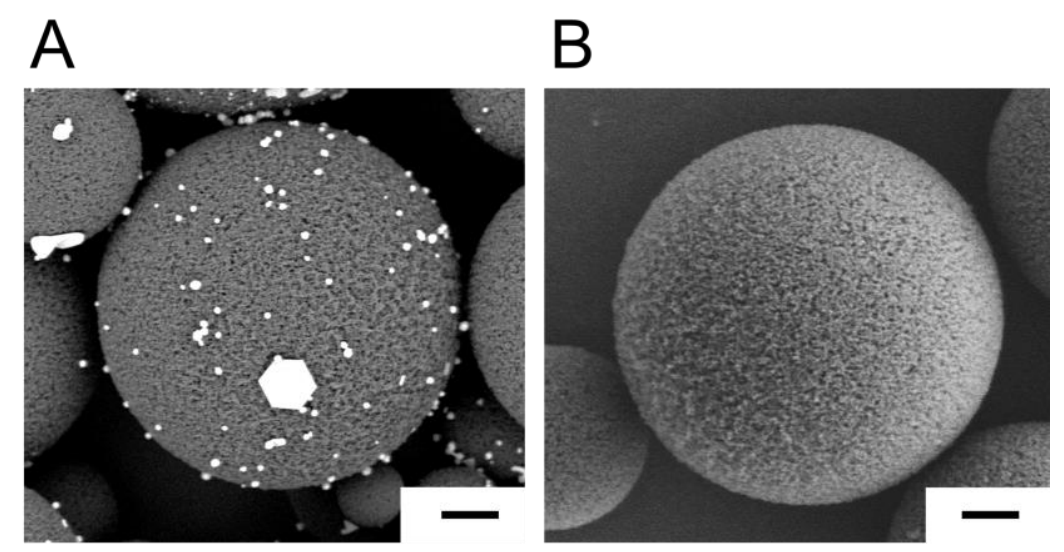

\section{C}
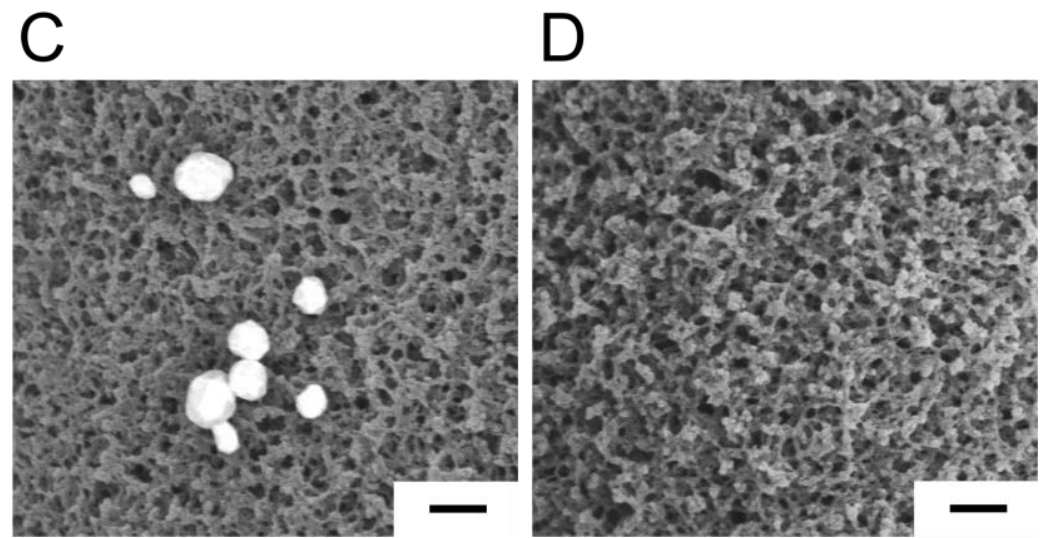

Figure S8. SEM images for Au-TA- $p$ MS from the gold adsorption experiment (A and C) and AuTA- $p$ MS from the gold desorption experiment (B and D). Scale bars: $2 \mu \mathrm{m}(\mathrm{A}-\mathrm{B})$ and $400 \mathrm{~nm}$ (BD). 


\section{REFERENCES}

(1) Adhikari, B. B.; Gurung, M.; Alam, S.; Tolnai, B.; Inoue, K. Kraft Mill Lignin - A Potential Source of Bio-Adsorbents for Gold Recovery from Acidic Chloride Solution. Chem. Eng. J. 2013, 231, 190-197. https://doi.org/10.1016/j.cej.2013.07.016.

(2) Gurung, M.; Adhikari, B. B.; Kawakita, H.; Ohto, K.; Inoue, K.; Alam, S. Recovery of $\mathrm{Au}(\mathrm{III})$ by Using Low Cost Adsorbent Prepared from Persimmon Tannin Extract. Chem. Eng. J. 2011, 174 (2-3), 556-563. https://doi.org/10.1016/j.cej.2011.09.039.

(3) Farnad, N.; Farhadi, K.; Voelcker, N. H. Polydopamine Nanoparticles as a New and Highly Selective Biosorbent for the Removal of Copper (II) Ions from Aqueous Solutions. Water. Air. Soil Pollut. 2012, 223 (6), 3535-3544. https://doi.org/10.1007/s11270-0121131-7. 